\title{
Abusadores Sexuais Adultos e Adolescentes no Sul do Brasil: Pesquisa em Denúncias e Sentenças Judiciais
}

\author{
Ana Maria Franchi Pincolini' ${ }^{1}$ \\ Centro de Referência Especializado de Assistência Social da Fundação \\ de Assistência Social de Caxias do Sul, Caxias do Sul, Rio Grande do Sul, Brasil \\ Cláudio Simon Hutz \\ Departamento de Psicologia do Desenvolvimento e da Personalidade da Universidade \\ Federal do Rio Grande do Sul, Porto Alegre, Rio Grande do Sul, Brasil
}

\begin{abstract}
Resumo
Este estudo investigou o abuso sexual perpetrado por adultos e adolescentes em processos judiciais de natureza criminal encaminhados à $1^{\mathrm{a}}$ e $2^{\mathrm{a}}$ Varas da Infância e Juventude de Porto Alegre entre os anos de 2003 e 2007. Foram coletadas informações sobre abusadores, vítimas, tipos de abuso e desfecho dos processos objetivando caracterizar os abusadores e comparar o perfil das vítimas e o tipo de abuso (intrafamiliar ou extrafamiliar). Foram encontrados 241 processos, sendo 229 elegíveis para a pesquisa. Os resultados indicaram que entre abusadores adultos predominou o abuso sexual intrafamiliar contra vítimas do sexo feminino, sendo os principais abusadores pais e padrastos das vítimas. Entre abusadores adolescentes houve predomínio do abuso sexual extrafamiliar contra vítimas do sexo masculino, especialmente vizinhos. Estes resultados sugerem que pode haver diferenças no perfil das vítimas e no tipo de abuso perpetrado por adultos e adolescentes, hipótese que merece ser testada em estudos futuros.
\end{abstract}

Palavras-chave: Abuso sexual, abusadores sexuais adultos, abusadores sexuais adolescentes.

\section{Sexual Offender Adults and Adolescents in South of Brazil: Research with Complaints and Veredicts}

\begin{abstract}
This study investigated sexual abuse perpetrated by adults and teenagers in the criminal proceedings referred to the $1^{\text {st }}$ and $2^{\text {nd }}$ Childhood and Youth's Courts of Porto Alegre between 2003 and 2007. The information collected for abusers, victims, types of abuse and the outcomes of processes aiming to characterize and compare the profile of abusers and victims and the type of abuse (intrafamilial or extrafamilial). After being collected, the data were tabulated and categorized, and of the 241 cases, 229 were eligible for the study. The results indicated that among adult abusers there was a predominance of intrafamilial sexual abuse against female victims and that the main abusers were fathers and stepfathers. Among adolescents abusers, extrafamilial sexual abuse against male victims predominated, especially against neighbors. These results suggest that there may be differences in the profile of the victims and the type of abuse perpetrated by adults and adolescents, a hypothesis that should be tested in future studies.
\end{abstract}

Keywords: Sexual abuse, adult sexual abusers, adolescent sexual abusers.

Endereço para correspondência: Rua Mário de Boni, 1894, Apto. 1001, Bairro Floresta, Caxias do Sul, RS, Brasil 95012-580. E-mail: anissyma@yahoo.com.br

Agradecimento: Esse estudo foi autorizado judicialmente e contou com o apoio dos Magistrados Dr. Daltoé Cezar e Dr. Breno Beutler Jr. e de duas profissionais da $1^{\mathrm{a}}$ e $2^{\mathrm{a}}$ Varas da Infância e Juventude de Porto Alegre, a Assistente Social Vânea Maria Visnievski e a Psicóloga Betina Tabajaski. 


\section{Delincuentes Sexuales Adultos y Adolescentes en el Sur de Brasil: Investigación con Denuncias y Sentencias Judiciales}

\section{Resumen}

Este estudio investigó los abusos sexuales perpetrados por adultos y adolescentes em procedimientos legales presentados em dos Tribunales de la Niñez y la Juventud de Porto Alegre entre 2003 y 2007. Se recolectó información sobre agresores, víctimas, tipo de abuso y sentencias para comparar el perfil de las víctimas, de los abusadores y el tipo de abuso (intrafamiliar o extrafamiliar). Fueran encontradas 241 demandas judiciales, con 229 elegibles para el estudio. Los resultados indicaron que entre los abusadores adultos predominó el abuso sexual intrafamiliar y las víctimas mujeres predominan sobre los hombres. Padres y padrastros son los principales perpetradores. Entre los adolescentes el abuso sexual extrafamiliar contra niños fue más frecuente, sobre todo contra los vecinos. Estos resultados sugieren que puede haber diferencias en el perfil de víctimas y en el tipo de abuso perpetrado por adultos y adolescentes, una hipótesis que merece ser investigada en estudios futuros.

Palabras clave: Abuso sexual, abusadores sexuales adultos, adolescentes delincuentes sexuales.

A despeito da evolução nos debates acerca dos direitos de crianças e adolescentes, a violência sexual (VS) é um fenômeno que ocorre em escala mundial, cuja real prevalência é desconhecida e provavelmente subnotificada (Cohen \& Gobetti, 2003; Sanderson, 2005). A VS contra crianças e adolescentes assume basicamente duas formas: Abuso Sexual (AS) e Exploração Sexual de Crianças e Adolescentes (ESCA). O AS consiste no envolvimento de crianças/adolescentes em atividades sexuais às quais são incapazes de compreender completamente devido ao seu estágio de desenvolvimento. Tais atividades têm como objetivo principal a gratificação/ satisfação sexual dos abusadores, de modo que, entre eles e suas vítimas, ocorre uma relação desigual de responsabilidade, confiança ou poder (Organização Mundial da Saúde [OMS], 1999). Já a ESCA compreende atos de natureza sexual envolvendo crianças e adolescentes nos quais há "remuneração" em espécie para a criança/adolescente e/ou para terceiros, que participam de uma rede de exploração sexual infanto-juvenil em que crianças/adolescentes são tratados como mercadorias e objetos sexuais. Portanto, é o caráter comercial e mercantil que distingue os dois conceitos (Faleiros, 2000). Este estudo não abordou processos envolvendo ESCA, somente AS.

Quando ocorre dentro da família, o AS é chamado Abuso Sexual Intrafamiliar (ASI) e, nesse caso, os abusadores têm para com as ví- timas laços de consanguinidade, afetividade e/ ou responsabilidade. Várias pesquisas indicam que o grupo familiar tem sido o palco da maior ocorrência do AS de crianças/adolescentes (Habigzang, Koller, Azevedo, \& Machado, 2005; Pfeiffer \& Salvagni, 2005), sendo que as vítimas são geralmente meninas (Cohen \& Gobetti, 2003; Pelisoli, Pires, Almeida, \& Dell'Aglio, 2010; Polanczyc, Zavaschi, Benetti, Zenker, \& Gammerman, 2003).

O AS contra meninos é socialmente menos reconhecido (Almeida, Penso, \& Costa, 2009; Kristensen, 1996; Pfeiffer \& Salvagni, 2005), de modo que possivelmente seja ainda mais subnotificado do que no caso das meninas, já que as relações abusivas podem ser percebidas como associadas à homossexualidade (Cohen \& Gobetti, 2003; Kristensen, 1996). De fato, a preocupação dos familiares e da própria vítima em relação à repercussão do AS sobre a orientação sexual de meninos vítimas é relatada em estudos (Pfeiffer $\&$ Salvagni, 2005; Sanderson, 2005). Além disso, a situação de subordinação característica da vitimização sexual contraria as representações sociais relacionadas à masculinidade e gera sentimentos de vergonha em vítimas e familiares, dificultando a revelação do AS (Weiss, 2010).

Ao examinarem o AS contra meninos em 11 estudos nacionais, Hohendorff, Habigzang e Koller (2012) indicam grande variação nos dados, citando estudos nos quais as prevalên- 
cias variaram de $8,5 \%$ a $40,7 \%$ de vitimização no sexo masculino. Os autores enfatizam que a maior prevalência, encontrada no único estudo com amostra não clínica (Polanczyc et al., 2003), reforça a hipótese da subnotificação, uma vez que as populações clínicas refletem casos que efetivamente chegaram às autoridades competentes.

Nem sempre o AS deixa vestígios físicos e frequentemente é revelado em momento muito posterior ao fato (Pfeiffer \& Salvagni, 2005) de modo que muitos abusadores acabam absolvidos devido à insuficiência de provas (Artigo 386 do Código de Processo Penal [CPP], 1941) e ao benefício da dúvida (in dubio pro reo) - a existência de dúvida quanto à autoria favorece o acusado (Paulo \& Maia, 2004). Outro aspecto relacionado à responsabilização dos abusadores é princípio constitucional do duplo grau de jurisdição, que prevê a possibilidade de recorrer a um órgão judiciário de instância superior (Paulo $\&$ Maia, 2004). Por isso, muitas vezes, ocorre que sentenças de primeira instância sejam reformuladas.

Estimativas internacionais indicam que em torno de $30 \%$ dos casos de AS são praticados por menores de 18 anos (Oliver, 2007; Sanderson, 2005). O AS perpetrado por adolescentes em geral é cometido por irmãos, meio irmãos e primos, bem como por adolescentes do sexo feminino, atuando como babás, motivadas por curiosidade sexual e oportunidades de experimentação (Sanderson, 2005).

No entanto, as características da adolescência exigem ponderação para avaliar uma situação como sendo de AS. Como a entrada na puberdade gera aumento de fantasias sexuais, é importante distinguir o AS das atividades sexuais exploratórias e consensuais, comuns nessa fase. Quanto maior a diferença de idade entre a criança e o adolescente, maior a probabilidade de ser uma situação de AS (Itzin, 2002). É considerável uma diferença etária de, pelo menos, cinco anos (quando as vítimas são menores de 12 anos) e dez anos (quando as vítimas têm entre 13 e 16 anos; Finkelhor \& Hotaling, 1984). Além da idade, é importante considerar outros fatores, como a presença de violência física, ameaças para garantir o sigilo e sentimentos de culpa e constrangimento da criança com relação à atividade (Itzin, 2002). Isso deve ser observado no caso de situações que envolvem crianças/adolescentes que ocupem posição de liderança no grupo e tenham reputação/status que amedronte as mais novas, ou ainda irmãos mais velhos com autoridade ou com a tarefa de tomar conta dos mais novos.

Ao discutir o AS perpetrado por adolescentes, Print e Morrison (2002) indicam fatores de risco, como problemas de socialização, poucas amizades íntimas, baixa habilidade social e relacional, dificuldades escolares, distúrbios de conduta, baixa autoestima e distúrbios afetivos, de modo que a atividade sexual pode ser usada como compensação para problemas emocionais e relacionais. Experiências de violência doméstica, abuso físico, emocional, e mesmo AS também são predisponentes (Print \& Morrisson, 2002).

Recentemente, um estudo nacional (Costa, Junqueira, Ribeiro, \& Meneses, 2011) com sete adolescentes abusadores sexuais que cometeram AS contra crianças (irmãos, primos) que estavam sob seus cuidados descreveu uma dinâmica familiar que foi, em certa medida, promotora do cenário que favoreceu o AS. Os adolescentes eram responsáveis pela alimentação, banho e por acompanhar as crianças menores à escola. Essa posição de responsabilidade e cuidado em relação às outras crianças da casa mudava à noite, com a chegada dos pais, quando todos ficavam no mesmo nível hierárquico, sujeitos à obediência e aos mesmos castigos e repreensões. Outro aspecto identificado nesse estudo foi a autopercepção dos adolescentes abusadores como "trabalhadores domésticos", de modo que o papel deles na família alternava a posição de dominante (em que se utilizavam das crianças menores como objetos de satisfação/experimentação sexual) e dominados (convertidos em "criados" dos pais e sem terem atendidas suas necessidades de apoio e proteção). Aspectos como este tornam difusos os limites entre vítimas e abusadores (Sanderson, 2005) e reforçam a necessidade de que adolescentes que cometeram AS sejam vistos para além da criminalização, como vítimas de uma infância sem proteção. 
Em relação à responsabilização de adolescentes, no Brasil, são penalmente inimputáveis os menores de 18 anos (Constituição da República Federativa do Brasil, 1988). No entanto, inimputabilidade penal não significa irresponsabilidade pessoal ou social. Embora predomine no senso comum certa confusão entre inimputabilidade e impunidade, a sensação de que "nada acontece" aos adolescentes é equivocada e motivada pelo desconhecimento, já que a legislação prevê alternativas de responsabilização, reguladas pelo ECA (Estatuto da Criança e do Adolescente, 1990) e pelo Sistema Nacional de Atendimento Socioeducativo (SINASE; Lei Federal 12.594, 2012).

De acordo com o Artigo 103 do ECA (1990), qualquer conduta descrita como crime pelo Código Penal (CP, 1940), quando praticada por menores de 18 anos, não é chamada "crime", e sim "Ato Infracional" (AI). A responsabilização dos adolescentes difere daquela aplicada aos adultos, pois contempla a condição de pessoa em desenvolvimento, de modo que não estão previstas penas, e sim Medidas Socioeducativas (MSE), tais como advertência, obrigação de reparar o dano, prestação de serviços à comunidade (PSC), liberdade assistida (LA), semiliberdade e internação (privação de liberdade) em estabelecimento socioeducativo (Artigo 112 do ECA, 1990). A PSC (Artigo 117 do ECA, 1990) consiste em realizar tarefas gratuitas, de interesse da comunidade, junto a entidades assistenciais, hospitais, escolas, entre outros. No caso da LA (Artigo 118 do ECA, 1990), os adolescentes são acompanhados por um orientador. A equipe do programa de LA deve ser composta por profissionais de diferentes áreas do conhecimento, garantindo atendimento psicossocial com o fim de promover socialmente o adolescente e sua família (Lei Federal 12.594, 2012), auxiliar na ressignificação do AI, promover um espaço de escuta e reflexão e apresentar relatórios à autoridade judiciária (ECA, 1990). O ECA (1990) também prevê medidas de proteção (tratamento médico, psicológico ou psiquiátrico), que podem ser determinadas pelo juiz simultaneamente às MSE (Artigo 101, inciso V do ECA, 1990). A aplicação de MSE privativas de liberdade somente deve ocorrer em último caso, quando comprovadamente não for cabível outra solução (Lei Federal 12.594, 2012).

No Brasil há carência de estudos sobre abusadores adolescentes de modo que quase não há dados sobre prevalência ou características (Costa et al., 2011). Portanto, além de contribuir com a discussão acerca do AS, o presente estudo objetiva ampliar o conhecimento sobre abusadores adolescentes e contribuir para o preenchimento desta lacuna.

\section{Método}

\section{Delineamento}

Este é um estudo documental, exploratório e descritivo.

\section{Amostra}

Entre 2003 e 2007 foram encaminhados a $1^{\mathrm{a}}$ e $2^{\mathrm{a}}$ Varas da Infância e Juventude de Porto Alegre 241 processos criminais referentes a AS. Destes, 12 foram excluídos em função de que havia informações insuficientes sobre o número do processo, inviabilizando o acesso, de modo que a amostra finalizou em de 229 processos. $\mathrm{O}$ recorte temporal foi utilizado com a finalidade de encontrar o maior número possível de processos julgados. Foram considerados processos referentes a AS aqueles motivados por crimes/AI classificados como "contra a liberdade sexual" (Capítulo I, Título VI do Código Penal, 1940). Durante a realização desse estudo, o Código Penal sofreu alterações importantes por meio da Lei Federal 12.015 (2009). No entanto, como os dados examinados foram referentes a processos que ocorreram antes desse reordenamento na legislação, foi mantida a descrição das condutas até então vigentes, presente nas denúncias e sentenças examinadas.

\section{Instrumentos}

Os documentos examinados consistiram em material impresso (denúncias do Ministério Público [MP]) e eletrônico (sentenças).

\section{Procedimentos}

A coleta de dados foi feita a partir da leitura exaustiva das denúncias e das sentenças dis- 
poníveis no site do Tribunal de Justiça do RS. Para tal, foi elaborada uma Ficha de Coleta de Dados contendo informações referentes às vítimas, aos acusados e ao processo judicial. Em relação às vítimas, foram coletados os seguintes dados: idade, sexo e relação com os acusados (dado que permitiu a posterior categorização dos crimes/AI como AS intrafamiliar ou extrafamiliar). Em relação aos acusados, foram coletadas as seguintes informações: sexo, idade (a partir da qual foram categorizados os crimes (praticados por maiores de 18 anos) e os AI (praticados por adolescentes), estado civil, grau de instrução e ocupação. Em relação ao processo foram coletados os seguintes dados: cidade em que ocorreu o AS, desfecho do processo na justiça de $1^{\circ}$ Grau (condenatório, absolutório ou em tramitação) e de $2^{\circ}$ Grau, quando disponível. A coleta de dados a partir das denúncias ocorreu de março a junho de 2009 e a busca pelas sentenças no site e coleta dos dados das mesmas ocorreu de junho de 2009 a abril de 2010. O estudo foi autorizado judicialmente e respeitou as normativas éticas da Resolução 196/96 do Conselho Nacional de Saúde, tendo sido aprovado pelo Comitê de Ética em Pesquisa da Universidade Federal do Rio Grande do Sul (Protocolo 2009/14, registro 25000.089325/2006-58).

\section{Análise dos Dados}

Após a coleta, os dados foram tabulados em um banco de dados no Microsoft Excel e foram calculadas as médias $(M)$ e desvios padrão $(D P)$ dos dados quantitativos. Os dados nominais foram categorizados e foram contadas as frequências e calculadas as percentagens, quando cabí- vel. Esses resultados foram, então, confrontados com pesquisas anteriores e com a literatura especializada e serão apresentados a seguir.

\section{Resultados}

\section{Descrição Geral}

Predominaram processos da capital e de cidades da região metropolitana do RS (76\%), enquanto $24 \%$ dos processos eram oriundos de cidades do interior do RS. As datas dos fatos denunciados abrangeram o período compreendido entre 1996 e 2007. O total de abusadores e de vítimas foi superior ao total de processos porque houve processos com mais de um acusado e processos com mais de uma vítima, totalizando 255 abusadores e 294 vítimas.

Considerando a amostra como um todo, houve predomínio de ASI. Dos 229 processos, $123(53,7 \%)$ descreveram situações em que os abusadores tinham relações de parentesco e/ou responsabilidade para com as vítimas. Em 100 processos $(43,7 \%)$ não havia parentesco/responsabilidade entre vítimas e abusadores e seis $(2,6 \%)$ descreviam AS simultaneamente intra e extrafamiliares. Nesses casos, ou havia abusadores múltiplos, com diferentes relações de parentesco com a vítima ou, ao contrário, múltiplas vítimas, cada uma com diferentes relações de parentesco com o abusador.

Dos 229 processos, $170(74 \%)$ se referiam a AS praticados por maiores de 18 anos (crimes), enquanto 57 (25\%) se referiram a AI, pois um ou mais adolescentes constavam como acusados. Em dois processos (menos de 1\%) houve abusadores adultos e adolescentes agindo em conjunto (Tabela 1).

\section{Tabela 1}

\section{Descrição Geral dos Dados}

\begin{tabular}{lccc}
\hline Condutas & Processos & Abusadores & Vítimas \\
\hline Crimes (cometidos somente por adultos) & 170 & 185 & 224 \\
AI (cometidos somente por adolescentes) & 57 & 70 & 66 \\
Crime/AI (cometidos por adultos e adolescentes agindo em conjunto) & 02 & - & 04 \\
\hline TOTAL & 229 & 255 & 294 \\
\hline
\end{tabular}




\section{Perfil dos Abusadores}

Adultos. Dos 255 acusados, 185 (72,5\%) eram maiores de 18 anos. A maioria deles (174 ou $94 \%$ ) era do sexo masculino, sendo $11(6 \%)$ do sexo feminino. Na época do crime, eles tinham idades em torno de 40 anos, embora com bastante variação $(M=39,54 ; D P=13,76$ anos). Dos 185 acusados adultos, 106 (57,3\%) viviam maritalmente na época do crime.

Foram encontradas informações sobre o grau de instrução de 158 acusados adultos. A maior parte deles possuía escolaridade entre a $5^{\circ}$ e $8^{\circ}$ série do ensino fundamental $(37,8 \%)$, enquanto $29,7 \%$ tinham escolaridade entre a $1^{\circ} \mathrm{e}$ a $4^{\circ}$ série. Somente $8,6 \%$ tinham o ensino médio (completo ou não) e menos de $2 \%$ haviam ingressado em um curso superior. Além disso, $7,6 \%$ eram analfabetos ou semialfabetizados. As ocupações mais frequentes foram nas áreas de construção civil $(10,8 \%)$, agricultura $(10,8 \%)$ e transportes (6,5\%). Além disso, 38 acusados $(20,5 \%)$ estavam desempregados ou atuavam na informalidade na época do crime.

Adolescentes. Todos os 70 adolescentes acusados de AS eram do sexo masculino, com média de idade inferior a 15 anos $(M=14,66$ anos, $D P=1,59$ anos). Os adolescentes apresentaram grau de instrução defasado em relação à idade cronológica: $43 \%$ tinham escolaridade entre a $5^{\mathrm{a}}$ e a $6^{\mathrm{a}}$ série, $14 \%$ entre a $1^{\circ}$ e a $4^{\circ}$ série e $7 \%$ estavam no ensino médio. Seis $(8,6 \%)$ dos 70 adolescentes abusadores trabalhavam irregularmente no mercado informal na época do AI. Em seis $(10,5 \%)$ dos 57 processos tendo adolescentes como acusados o AI foi cometido por um grupo de adolescentes.

\section{Perfil das Vítimas}

Como já foi dito anteriormente, o número de vítimas foi superior ao número de processos porque houve casos com mais de uma vítima. De um total de 294 vítimas, 224 (76,2\%) foram abusadas por adultos, $66(22,4 \%)$ por adolescentes e quatro $(1,4 \%)$ por adultos e adolescentes agindo em conjunto. A principal diferença encontrada no perfil de vítimas de abusadores adultos e de vítimas de abusadores adolescentes foi em relação ao sexo.

Das 224 vítimas de adultos, 175 (78\%) eram meninas, enquanto 49 (22\%) eram do sexo masculino. As vítimas de abusadores adultos tiveram média de idade igual a 8,23 anos $(D P=3,56$ anos). Contrariamente, as vítimas de abusadores adolescentes foram prioritariamente do sexo masculino. Das 66 vítimas de adolescentes 40 (61\%) eram meninos, com média de idade igual a 7,73 anos $(D P=3,08$ anos; Tabela 2$)$.

\section{Tabela 2}

Acusados Adultos e Adolescentes X Sexo

\begin{tabular}{lcccccc}
\hline \multirow{2}{*}{ Acusados } & \multicolumn{2}{c}{ Sexo dos acusados } & \multicolumn{4}{c}{ Sexo das vítimas } \\
\cline { 2 - 7 } & Feminino & Masculino & Total & Feminino & Masculino & Total \\
\hline Adultos & 11 & 174 & 185 & 175 & 49 & 224 \\
Adolescentes & - & 70 & 70 & 26 & 40 & 66 \\
Ambos & - & - & - & 01 & 03 & 04 \\
\hline Total & 11 & 194 & 255 & 202 & 92 & 294 \\
\hline
\end{tabular}

\section{Tipo de AS}

Dos 170 processos envolvendo AS cometido por adultos, $104(61,2 \%)$ descreveram situações de ASI, 60 (35,3\%) de AS extrafamiliar e seis $(3,5 \%)$ podem ser classificados simultaneamente como ASI e AS extrafamiliar. Somente 22
(12\%) dos 185 abusadores adultos eram completamente desconhecidos das vítimas enquanto 79 deles $(43 \%)$ desempenhavam a função parental em relação a elas.

O AS cometido por adolescentes foi predominantemente extrafamiliar. Em 40 (70,2\%) 
dos 57 processos, os adolescentes abusadores não tinham relação de parentesco com as vítimas. Em 17 processos $(29,8 \%)$ houve ASI

(Tabela 3).

Tabela 3

Tipo de Abuso Cometido por Adultos e Adolescentes

Tipo de Abuso sexual

\begin{tabular}{lccc}
\cline { 2 - 4 } Processos & Intrafamiliar & Extrafamiliar & Intra/Extra \\
\hline Crimes $(N=170)$ & $61,2 \%$ & $35,3 \%$ & $3,5 \%$ \\
AI $(N=57)$ & $29,8 \%$ & $70,2 \%$ & - \\
\hline
\end{tabular}

Nos dois casos em que abusadores adultos e adolescentes agiram em conjunto, configurando uma situação em que, simultaneamente, houve crime e AI, o AS foi extrafamiliar. Do total de 70 abusadores adolescentes, 50 (71\%) não tinham relação de parentesco com as vítimas e 20 (29\%) tinham algum parentesco, configurando situações de ASI. É interessante notar que exatamente metade dos acusados adolescentes eram vizinhos de suas vítimas. Somando vizinhos e conhecidos obteve-se $66 \%$ dos acusados adolescentes do presente estudo.

\section{Desfecho dos Processos}

Crimes. Com relação ao desfecho, dos 170 processos envolvendo acusados adultos, 32 estavam em tramitação e 138 já estavam sentenciados no $1^{\circ}$ Grau. Dos sentenciados, 88 (63,8\%) tiveram sentença condenatória e 50 (36,2\%), absolutória. Em relação ao duplo grau de jurisdição, 67 processos possuíam também sentença de $2^{\circ} \mathrm{Grau}$ e em mais da metade deles (40 processos ou $60 \%$ ) a sentença foi reformada, resultando no seguinte: em 23 processos a condenação foi mantida, mas a pena foi reduzida, em 11 houve mudança da sentença (condenação no $1^{\circ}$ Grau seguida de absolvição no $2^{\circ} \mathrm{Grau}$ ), em cinco a condenação e a duração da pena foram mantidas mas houve alteração do regime de cumprimento e em um a sentença absolutória no $1^{\circ}$ Grau foi revertida para sentença condenatória no $2^{\circ} \mathrm{Grau}$.

$A I$. somente foi possível verificar o desfecho de 24 processos de AS cometido por adolescentes. Destes, 23 tiveram sentença condenatória. Foram 12 LA, cinco PSC, três advertências e duas internações. Em um caso houve advertência e PSC simultaneamente. Em três dos 24 casos com sentença disponível houve requisição de tratamento psicológico/psiquiátrico como medida de proteção concomitante à MSE.

\section{Discussão}

Embora ainda persista no senso comum o mito de que os abusadores sexuais são pessoas externas à família (Granjeiro \& Costa, 2008), os dados das pesquisas têm continuamente chegado a conclusões opostas, como no caso do presente estudo. A predominância de vítimas do sexo feminino, na faixa etária dos cinco aos 10 anos de idade, encontrada por diversos autores (Cohen \& Gobetti, 2003; Habigzang et al., 2005; Pelisoli et al., 2010; Polanczyc et al., 2003), também foi corroborada.

A porcentagem de AS cometido por adolescentes encontrada na presente pesquisa foi muito próxima à da literatura citada (Oliver, 2007; Sanderson, 2005). No entanto, a carência de estudos nacionais sobre o tema torna difícil saber o quanto estes dados refletem a realidade brasileira. Além disso, predomina no senso comum a suposição de que abusadores sexuais adultos se utilizariam de adolescentes para que os mesmos cometam AI em função da responsabilização diferenciada, sendo este um dos argumentos dos defensores da redução da maioridade penal (Koerner, 1997). No entanto, os dados encontrados em relação ao concurso de abusadores adultos e abusadores adolescentes não apoiaram esta hipótese já que somente dois $(0,9 \%)$ dos 229 pro- 
cessos descreveram participação simultânea de adultos e adolescentes como acusados de AS. Ao contrário, nos processos examinados, a maioria dos adolescentes cometeu o AI sozinho ou com outros adolescentes.

Segundo Araújo (2008) é importante levar em conta o contexto em que é cometido o AS por abusadores adolescentes, uma vez que o envolvimento de amigos poderia influenciar essas condutas. A adolescência é uma fase de experimentação e autoafirmação em relação à sexualidade, de modo a que a influência do grupo de amigos é indicada como um fator predisponente a cometer AS como forma de demonstração de virilidade para os pares (Araújo, 2008; Print \& Morrison, 2002). No entanto, na presente pesquisa, somente seis $(10,5 \%)$ dos 57 AI tiveram mais de um adolescente abusador. Assim, são necessários estudos com amostras maiores para esclarecer a relação entre AI de natureza sexual e pressões de grupo.

Em relação ao perfil, abusadores adultos apresentaram características semelhantes às encontradas em pesquisa realizada anteriormente no Rio Grande do Sul, a qual aponta o baixo grau de instrução e atuação em profissões de baixa qualificação, em geral no mercado informal (Habigzang et al., 2005). O desemprego, indicado como fator de risco para violência intrafamiliar, também foi encontrado neste estudo. Em função de gerar conflitos e estresse entre os membros da família e de colocar o pai/padrasto como principal cuidador das crianças, o desemprego e a informalidade podem oportunizar o AS (Koller \& De Antoni, 2004), especialmente o ASI. Algumas características dos abusadores adolescentes coincidiram com aquelas dos abusadores adultos, em especial o baixo grau de instrução, expresso em uma defasagem entre a idade cronológica e o nível de escolaridade correspondente e o engajamento em subempregos. Alguns autores (Acosta \& Barker, 2003; Araújo, 2008) referem que cometer AS na adolescência é um fator de risco para continuar sendo um abusador sexual de crianças quando adulto. A semelhança nestes aspectos do perfil de abusadores adultos e abusadores adolescentes pode ser indicativa deste risco.
O perfil das vítimas e o tipo de AS foi muito diferente no caso de abusadores adultos e abusadores adolescentes. A maioria das vítimas de abusadores adultos foram meninas e houve predomínio de ASI, com boa parte dos abusadores desempenhando a função parental. Contrariamente, o AS cometido por abusadores adolescentes foi predominantemente dirigido a vítimas do sexo masculino, sem relação de parentesco (metade dos adolescentes abusadores eram vizinhos das vítimas). Esses achados diferiram de estudos internacionais (Sanderson, 2005) e surpreenderam os pesquisadores.

Como já relatado, em seu estudo com adolescentes abusadores, Costa et al. (2001) descreveram situações em que tais adolescentes eram responsáveis pelas tarefas domésticas e pelo cuidado das demais crianças da casa. Essa situação, em grande medida gerada pelas dificuldades socioeconômicas das famílias, que não têm como custear espaços mais adequados em uma realidade de carência de vagas nas escolas infantis gratuitas, era potencialmente geradora de uma confusão de papéis em função da alternância de poder que tais adolescentes experimentavam dentro da família. Segundo as autoras, essa dinâmica familiar se constituiu em um fator de risco para o AS. Um aspecto semelhante foi discutido por Sanderson (2005) em relação a adolescentes abusadoras que atuavam como babás. A dificuldade de assumir papéis contraditórios de poder/ responsabilidade em relação a crianças menores e características da adolescência, tais como impulsividade e questionamentos em relação à própria identidade favoreceriam o AS.

$\mathrm{Na}$ realidade brasileira a maior parte das notificações de AS se refere a famílias de baixa renda, que, com dificuldades de satisfação até mesmo de suas necessidades básicas, acabam lançando mão dos filhos adolescentes como responsáveis pelo trabalho doméstico e pelo cuidado das crianças menores (Costa et al., 2011). Quando não dispõem de recursos para custear cuidadores adultos ou instituições educativas adequadas para os filhos pequenos, as famílias pobres costumam organizarem-se em redes familiares de ajuda mútua, caracterizadas pela presença de avós, tios, primos e outros parentes 
diversos que residem no entorno, de modo que as crianças circulam por várias casas e têm múltiplos cuidadores (Fonseca, 2005). Além disso, quando não dispõem de uma rede de apoio na família extensa, é comum que tais famílias solicitem a vizinhos o cuidado temporário e a supervisão das crianças. Em decorrência disso, nesse contexto de circulação de crianças (Fonseca, 2005), presume-se que seja frequente que adolescentes tenham acesso a filhos de vizinhos que estão sendo cuidados. Também é comum que sejam eles próprios solicitados a "ficar com as crianças" ou a "olhar as crianças" da vizinhança por algum tempo. Se a disponibilidade da vítima e a ausência de supervisão adulta criam oportunidades para o AS (Print \& Morrison, 2002) e há dificuldades para que os adolescentes consigam dar conta da alternância de papéis de diferentes níveis hierárquicos, pode-se pensar que, mesmo não sendo familiares de vítimas, tais adolescentes vivenciem situação análoga em relação às crianças das quais tomam conta. Eles próprios estão, na maior parte do tempo, no mesmo nível hierárquico de seus vizinhos menores, necessitando, também, de cuidados e de proteção. Quando solicitados a cuidar das crianças que circulam, tendem a ocupar temporariamente uma posição de poder em relação a elas, mas também de subordinação em relação àqueles que thes impuseram essa tarefa. Somada à impulsividade característica da adolescência e à presença de impulsos/fantasias sexuais dirigidos às crianças das quais estão tomando conta, tal dinâmica relacional poderia ser uma hipótese explicativa para a elevada frequência de AS dirigida a crianças da vizinhança, encontrada no presente estudo.

Em relação à predominância de vítimas do sexo masculino, encontrada neste estudo, na sociedade brasileira, tradicionalmente, não é comum que adolescentes do sexo masculino brinquem com meninas menores sem nenhuma supervisão de um adulto. Também não é frequente que sejam solicitados a tomar conta de crianças do sexo feminino. Interações entre crianças menores do sexo masculino e adolescentes do sexo masculino são mais frequentes, seja na escola, em brincadeiras com vizinhos ou na prática de esportes, como o futebol, por exemplo. Assim, ao ter as vítimas disponíveis em sua casa para serem cuidadas ou quando solicitados a tomar conta das vítimas, sendo essas vítimas mais comumente meninos (já que meninas tradicionalmente não são "deixadas" com meninos na sociedade brasileira) criar-se-iam as condições para o AS. Esse maior "acesso" dos adolescentes do sexo masculino a crianças também do sexo masculino em um contexto de cuidados temporários é uma hipótese para explicar a predominância de vítimas do sexo masculino encontrada nesse estudo. Logicamente, seriam necessários mais estudos com abusadores sexuais adolescentes, com amostras maiores e análises mais aprofundadas, para apoiar hipóteses como esta, já que a mesma se baseia em dados intuitivos.

Em relação à responsabilização dos abusadores adultos, os dados apontaram que recorrer ao $2^{\circ}$ Grau foi vantajoso na maior parte dos casos. Além disso, como muitos abusadores condenados conquistam o direito de recorrer em liberdade, o tempo decorrido entre o crime e a responsabilização tende a ser mais longo. Assim como entre os abusadores adultos predominaram sentenças condenatórias, os abusadores adolescentes também foram na maioria responsabilizados por seus atos. No entanto, chamou a atenção o fato de que, embora o tratamento psicológico seja uma das medidas de proteção que podem ser adotadas simultaneamente ao cumprimento da MSE (Artigo 101, inciso V do ECA, 1990), ele tenha sido solicitado em apenas três casos. Considerando o AS contra crianças algo extremamente grave e presumindo que o AS cometido na infância possa ser um fator de risco para futuros AS na idade adulta (Acosta \& Barker, 2003; Araújo, 2008), seria fundamental um espaço psicoterápico, de natureza preventiva e/ou interventiva. Cabe salientar que abusadores adolescentes precisam, também, de cuidados e de espaços nos quais possam ressignificar o ato abusivo e expressar sentimentos, temores e fantasias (Araújo, 2008; Costa et al., 2011). A dificuldade de conter impulsos e a carência de intimidade e espaços de diálogo e continência afetiva nas relações familiares e sociais contribuem para a ocorrência do AS (Costa et al., 2011). Oportunizar tais espaços 
e, quando possível, inserir a família do adolescente nesse processo, pode prevenir a recorrência de AS no futuro.

\section{Considerações Finais}

Uma importante limitação deste estudo foi a análise dos dados ter base apenas em estatísticas descritivas, de modo que não foi possível estabelecer se as diferenças encontradas entre abusadores adultos e abusadores adolescentes são estatisticamente significativas. Além disso, a carência de estudos nacionais sobre abusadores sexuais adolescentes também limitou a discussão dos achados e sua confrontação com outras pesquisas. Geralmente os abusadores sexuais adolescentes não são incluídos em estudos sobre AS ou essa parcela de abusadores fica diluída nas pesquisas. É importante intensificar a pesquisa com abusadores sexuais adolescentes tanto do ponto de vista quantitativo (prevalência e características do AS) quanto qualitativo (trajetória de vida desses adolescentes). Estudos quantitativos, com amostras maiores, poderão corroborar ou confrontar os achados encontrados neste estudo. Caso corroborem, contribuirão para que as estimativas de prevalência de AS contra meninos estejam mais próximas da realidade. Estudos qualitativos com adolescentes abusadores poderiam contribuir na compreensão dos fatores motivadores do AS, bem como na proposição de intervenções para além da criminalização, em uma perspectiva preventiva e terapêutica. Estudos longitudinais poderiam esclarecer as relações entre cometer um AS na adolescência e tornar a cometê-lo na idade adulta e se constituiriam em valiosos subsídios para nortear intervenções junto a adolescentes abusadores sexuais e suas famílias e, assim, prevenir a recorrência do AS.

\section{Referências}

Acosta, F., \& Barker, G. (2003). Homens, violência de gênero e saúde sexual e reprodutiva: Um estudo sobre homens no Rio de Janeiro/Brasil. Rio de Janeiro, RJ: Instituto NOOS. Recuperado em www.promundo.org.br
Almeida, T. M. C., Penso, M. A. P., \& Costa, L. F. (2009). Abuso sexual infantil masculino: O gênero configura o sofrimento e o destino? Estilos da Clínica, 14(26), 46-67.

Araújo, S. A. (2008, 25-28 ago.). Violência sexual: Sentidos atribuídos por adolescentes identificados como praticantes de abuso sexual. Trabalho apresentado no seminário Fazendo Gênero 8 - Corpo, violência e poder, Florianópolis, SC, Brasil. Recuperado em março, 2009, de http:// www.fazendogenero8.ufsc.br/sts/ST20/Suzana_Almeida_Araujo_20.pdf

Código Penal. (1940, 31 dez.). Decreto-lei no 2.848, de 7 de dezembro de 1940. Diário Oficial da União.

Código de Processo Penal. (1941, 13 out.). Decreto-lei n ${ }^{\circ} 3.689$, de 3 de outubro de 1941. Diário Oficial da União.

Cohen, C., \& Gobetti, G. J. (2003). O incesto: O abuso sexual intrafamiliar. Recuperado em 10 de abril, 2008, de http://violênciasexual.org.br/textos/PDF/incesto_cohen.pdf.

Constituição da República Federativa do Brasil. (1988, 5 out.). Recuperado em 05 de março, 2010, de www.planalto.gov.br/.../constituicao/ constituiçao.htm

Costa, L. F., Junqueira, E. L., Ribeiro, A., \& Meneses, F. F. F. (2011). "Ministério da Obrigação" adverte: É preciso proteger os adolescentes ofensores sexuais. Avances en Psicología Latinoamericana, 29(1), 33-46.

Estatuto da Criança e do Adolescente. (1990). Lei Federal 8069. Recuperado em 17 de fevereiro, 2010, de www.planalto.gov.br/ccivil_03/Leis/ L8069.htm

Faleiros, E. T. S. (2000). Repensando os conceitos de violência, abuso e exploração sexual de crianças e adolescentes. Brasília, DF: Thesaurus.

Finkelhor, D., \& Hotaling, G. T. (1984). Sexual abuse in the national incidence study of child abuse and neglect: An appraisal. Child Abuse \& Neglect, 8, 23-33.

Fonseca, C. (2005). Concepções de família e práticas de intervenção. Saúde e Sociedade, 14(2), 50-59.

Granjeiro, I. A. C. L., \& Costa, L. F. (2008). O estudo psicossocial forense como subsídio para a decisão judicial na situação de abuso sexual. Psicologia: Teoria e Pesquisa, 24(2), 161-169. 
Habigzang, L. F., Koller, S. H., Azevedo, G. A., \& Machado, P. X. (2005). Abuso sexual infantil e dinâmica familiar: Aspectos observados em processos jurídicos. Psicologia: Teoria e Pesquisa, 21(3), 341-348.

Hohendorff, J. V., Habigzang, L. F., \& Koller, S. H. (2012). Violência sexual contra meninos: Dados epidemiológicos, características e consequências. Psicologia USP, 23(2), 395-415.

Itzin, C. (2002). Home truths about child sexual abuse: Influencing policy and practice. A reader. London: Routledge.

Koerner, R., Jr. (1997). A menoridade é carta de alforria? In M. Volpi (Ed.), Adolescentes privados de liberdade: A normativa nacional e internacional \& Reflexões sobre a responsabilidade penal dos adolescentes (pp. 109-156). São Paulo, SP: Cortez.

Koller, S. H., \& De Antoni, C. (2004). Violência intrafamiliar: Uma visão ecológica. In S. H. Koller (Ed.), Ecologia do desenvolvimento humano: Pesquisa e intervenção no Brasil (pp. 293-310). São Paulo, SP: Casa do Psicólogo.

Kristensen, C. H. (1996). Abuso sexual em meninos (Dissertação de mestrado, Programa de Pós-Graduação em Psicologia do Desenvolvimento, Instituto de Psicologia, Universidade Federal do Rio Grande do Sul, Porto Alegre, RS, Brasil).

Lei Federal 12.015. (2009, 10 ago.). Diário Oficial da União. Recuperado em 17 de fevereiro, 2010, de http://www.planalto.gov.br/ccivil_03/_ ato2007-2010/2009/lei/112015.htm

Lei Federal 12.594. (2012, 20 jan.). Diário Oficial da União. Recuperado em 18 de setembro, 2013, de http://www.planalto.gov.br/ccivil_03/ ato2011-2014/2012/lei/112594.htm

Oliver, B. E. (2007). Three steps to reducing child molestation by adolescents. Child Abuse \& $\mathrm{Ne}$ glect, 31, 683-689.
Organização Mundial da Saúde. (1999). Report of the consultation on child abuse prevention. Genebra, Suíça: Autor.

Paulo, V., \& Maia, J. (2004). Aulas de Direito Constitucional. Rio de Janeiro, RJ: Impetus.

Pelisoli, C., Pires, J. P. M., Almeida, M. E., \& Dell'Aglio, D. D. (2010). Violência sexual contra crianças e adolescentes: Dados de um serviço de referência. Temas em Psicologia, 18(1), 85-97.

Pfeiffer, L., \& Salvagni, E. P. (2005). Visão atual do abuso sexual na infância e adolescência. Jornal de Pediatria, 81(5 Supl.), S197-S204.

Polanczyk, G. V., Zavaschi, L., Benetti, S., Zenker, R., \& Gammerman, P. W. (2003). Violência sexual e sua prevalência em adolescentes de Porto Alegre, Brasil. Revista de Saúde Pública, 37(1), 8-14

Print, B., \& Morrison, T. (2002). Treating adolescents who sexually abuse others. In C. Itzin (Ed.), Home truths about child sexual abuse: Influencing policy and practice. A reader (pp. 290-313). London: Routledge.

Sanderson, C. (2005). Abuso sexual em crianças: Fortalecendo pais e professores para proteger crianças contra abuso sexual e pedofilia. São Paulo, SP: M Books.

Weiss, K. G. (2010). Male sexual victimization: Examining men's experiences of rape and sexual assault. Men and Masculinities, 12(3), 275-298. 